Reprod. Nutr. Dévelop., 1984, 24 (3), 235-238.

\title{
Effet de la lumière sur le développement embryonnaire dans deux lignées de poulets rendus maigres ou gras par sélection
}

\author{
M. F. BEDNARCZYK $\left({ }^{*}\right)$, J. SIMON (1), R. FERRE, B. LECLERCO \\ Station de Recherches avicoles, I.N.R.A., \\ Nouzilly, 37380 Monnaie, France. \\ (*) Centralny Ośrodek Badawczo-Rozwojowy Drobiarstwa, \\ OHDW Dworzyska 62-022, Swiątniki, Pologne.
}

Summary. Effect of light during embryonic development in two lines of chickens selected for leanness or fatness.

Two lines of chickens selected for leanness or fatness were compared as to rate of embryonic development and response to photo-acceleration during incubation (continuous fluorescent light). The lean line developed faster than the fat one. In both lines, light produced an earlier appearance of lung respiration and decreased mean incubation time independently of egg weight. At 17 days of incubation, plasma glucose levels and the difference between the two lines (slight hypoglycemia in the fat line) were unchanged after light.

\section{Introduction.}

Deux lignées de poulets " maigre » ou "grasse " ont été sélectionnées de façon divergente sur l'engraissement (Leclercq, Blum et Boyer, 1980). Comme il est décrit dans une revue récente, les différences entre ces deux lignées semblent uniquement d'origine métabolique (Simon et Leclercq, 1983). En particulier, une légère hypoglycémie s'établit dans la lignée grasse dès le développement embryonnaire (Simon et Leclercq, 1982). Dans ce travail, les deux lignées ont été comparées pour leur vitesse de développement et leur réponse à une photoaccélération pendant l'incubation (cf. références citées dans Bednarczyk et Coudert, 1984).

\section{Matériel et méthodes.}

Les pondeuses des deux lignées "maigre " ou " grasse " âgées de 53 semaines appartiennent à la génération $F 6$ et donc les embryons considérés

(1) La correspondance est à adresser à J. Simon. 
dans cette étude, à la F7 (Leclercq et al., 1980). Les œufs sont récoltés pendant 3 semaines, conservés dans les conditions standard et calibrés (au total : 261 œufs dans la lignée maigre ; 210 dans la lignée grasse). Pour l'incubation, ils sont répartis en fonction du calibre (A : 51-55 g, B : 56-60, C : 61-65, D : 66-70) et de la durée de stockage en deux lots éclairés ou non. L'éclairage est obtenu par des lampes fluorescentes ( blanc industrie » $20 \mathrm{~W}$ ), l'intensité au niveau des œufs variant dans l'incubateur de 520 à 2675 lux et dans l'éclosoir de 300 à 2000 lux (les œufs des différentes classes de poids ont été répartis pour tenir compte de cette hétérogénéité, l'intensité lumineuse n'ayant toutefois pas un effet marqué, cf. références citées dans Bednarczyck et Coudert, 1984). Pendant toute la période d'incubation, la température est enregistrée au niveau des œufs à l'aide d'un enregistreur électronique (Speedomax, MECI).

Aux $6^{\text {e }}$ et $17^{e}$ jours d'incubation, les œufs sont mirés pour dénombrer les œufs infertiles et la mortalité. Cette classification est confirmée par examen après cassage de l'œuf. Au $17^{\mathrm{e}}$ jour, des prélèvements de sang sont effectués dans la veine allantoïdienne d'embryons issus des œufs du calibre $61-65 \mathrm{~g}$ ( $\mathrm{n}=14$ ou 15 par lignée et par lot). La glycémie (dans le plasma) est mesurée par la méthode de la glucose oxydase à l'aide d'un analyseur de glucose (modèle 2, Beckman Instruments, Palo Alto, USA). Lors du transfert dans l'éclosoir (à 17 jours), le nombre d'embryons présentant une respiration pulmonaire (bec dans la chambre à air) est relevé. Afin d'apprécier une modification de la durée d'incubation, le nombre de poussins éclos est déterminé toutes les 8 heures à partir de l'apparition du premier poussin. Les résultats sont analysés par test $t, \chi^{2}$ ou analyse de variance.

\section{Résultats et discussion}

L'ensemble des résultats est présenté dans le tableau 1. Le pourcentage d'œufs fertiles et la mortalité précoce (1-6 jours) sont identiques quels que soient la lignée ou le traitement. A l'inverse, du $7^{\mathrm{e}}$ au $18^{\mathrm{e}}$ jour, la mortalité embryonnaire est significativement plus élevée dans la lignée maigre $(P<0,05)$, en particulier dans le lot éclairé. La cause de cette différence entre lignées est inconnue. II est, en effet, classiquement admis (Amer, 1962) que durant cette période, la mortalité embryonnaire reste très faible, comme dans le cas de la lignée grasse. Certaines modifications nutritionnelles imposées aux mères s'accompagnent toutefois d'une mortalité accrue pendant cette période (Leeson et al., 1979 ; Pearson et Herron, 1982).

Le pourcentage d'embryons qui présentent une respiration pulmonaire à 17 jours est plus élevé dans la lignée maigre $(P<0,05)$ ainsi que dans les lots éclairés $(P<0,01)$. Le développement embryonnaire plus rapide dans la lignée maigre est également confirmé par la mesure de la durée d'incubation (temps moyen) tout particulièrement dans le lot incubé à l'obscurité. L'effet n'est toutefois significatif $(P<0,05)$ qu'après regroupement des traitements. Dans les 2 lignées, la lumière diminue bien le temps moyen d'incubation $(P<0,01)$. L'effet de l'éclairement est particulièrement évident si on considère le pourcentage de poussins éclos jusqu'à 493 heures $1+29 \%$ dans la lignée maigre et 
+ $27 \%$ dans la lignée grasse après éclairement, données non présentées). En fonction du poids des œufs (données non présentées), la durée moyenne d'incubation augmente comme l'a démontré Coleman (1979) quel que soit le lot. L'effet de la lignée ou de la lumière se retrouve également dans toutes les classes de poids.

\section{TABLEAU 1}

Effet de la lumière sur le développement embryonnaire et la glycémie à 17 jours d'incubation dans deux lignées de poulets rendus maigres ou gras par sélection.

\begin{tabular}{|c|c|c|c|c|}
\hline & & \multicolumn{2}{|c|}{ Lignée } & \multirow{2}{*}{ Signification $(2)$} \\
\hline & & Maigre (M) & Grasse (G) & \\
\hline $\begin{array}{l}\text { Nb. d'œufs } \\
\text { mis en incubation (MEI) }\end{array}$ & $\begin{array}{l}O(1) \\
L(1)\end{array}$ & $\begin{array}{l}108 \\
111\end{array}$ & $\begin{array}{l}92 \\
84\end{array}$ & - \\
\hline $\begin{array}{l}\text { Fertilité (F) } \\
(\% \text { MEI) }\end{array}$ & $\begin{array}{l}O \\
L\end{array}$ & $\begin{array}{l}91,7 \\
91,9\end{array}$ & $\begin{array}{l}93,5 \\
89,3\end{array}$ & NS \\
\hline $\begin{array}{c}\text { 1-6 jours } \\
7-18 \text { jours } \\
19-22 \text { jours }\end{array}$ & $\begin{array}{l}O \\
L \\
O \\
L \\
O \\
L\end{array}$ & $\begin{array}{r}10,1 \\
10,8 \\
4,0 \\
7,8 \\
3,0 \\
4,9\end{array}$ & $\begin{array}{r}9,3 \\
14,3 \\
1,2 \\
1,3 \\
4,7 \\
5,3\end{array}$ & $\begin{array}{l}N S \\
M-G^{*} \\
N S\end{array}$ \\
\hline $\begin{array}{l}\text { \% embryons à respiration pulmonaire } \\
\text { à } 17 \text { jours }\end{array}$ & $\begin{array}{l}\mathrm{O} \\
\mathrm{L}\end{array}$ & $\begin{array}{l}54,1 \\
84,3\end{array}$ & $\begin{array}{l}44,2 \\
73,0\end{array}$ & $\begin{array}{l}M-G^{*} \\
O-L^{* *}\end{array}$ \\
\hline $\begin{array}{l}\text { Durée moyenne } \\
\text { d'incubation (h) }\end{array}$ & $\begin{array}{l}0 \\
L\end{array}$ & $\begin{array}{l}499,5 \\
494,0\end{array}$ & $\begin{array}{l}502,2 \\
494,8\end{array}$ & $\begin{array}{l}M-G^{*} \\
O-L^{* *}\end{array}$ \\
\hline $\begin{array}{l}\text { Taux d"éclosion } \\
\text { (\% œufs fertiles) }\end{array}$ & $\mathrm{O}$ & $\begin{array}{l}82,8 \\
76,5\end{array}$ & $\begin{array}{l}84,8 \\
78,7\end{array}$ & NS \\
\hline $\begin{array}{l}\text { Glycémie à } 17 \text { jours } \\
\text { (mg/100 ml) }\end{array}$ & $\begin{array}{l}O \\
L\end{array}$ & $\begin{array}{l}163 \pm 4 \\
167 \pm 5\end{array}$ & $\begin{array}{l}154 \pm 3 \\
152 \pm 5\end{array}$ & $\begin{array}{l}M-G^{* *} \\
O-L N S\end{array}$ \\
\hline
\end{tabular}

(1) $O$ : œufs incubés à l'obscurité : $L$ : œufs incubés à la lumière. $1 \%$.

(2) NS : pas de différence significative ; ${ }^{*}$ différence significative au seuil de $5 \% ;{ }^{* *}$ au seuil de

Le taux d'éclosion (\% des œufs mis en incubation ou fertiles) est légèrement plus élevé à l'obscurité. Les différences ne sont toutefois significatives ni pour la lignée, ni pour l'éclairement.

Enfin, l'éclairement ne modifie pas la glycémie mesurée au 17 e jour d'incubation et ne perturbe pas non plus la différence observée antérieurement entre les deux lignées (Simon et Leclercq, 1982). Pour une raison inconnue, dans le témoin, cette différence apparaît toutefois plus faible. Enfin, dans cette expérience, l'absence d'effet de la lumière sur la glycémie est contraire à la diminution rapportée par Coleman et Mc Daniel (1976). Il faut noter que l'origine des animaux diffère mais surtout que les mesures effectuées par ces derniers auteurs interviennent beaucoup plus précocément (4-10 jours d'incubation). 
Ainsi, l'accélération du développement embryonnaire par la lumière est confirmé. Ce mécanisme dont l'origine reste inconnue agit, semble-t-il, sans interaction dans les deux lignées qui pourtant diffèrent déjà durant le développement embryonnaire pour au moins la durée d'incubation et la glycémie. L'effet de la lumière apparaît additif comme l'avaient également observé Bohren et Siegel (1975) dans deux lignées sélectionnées de façon divergente pour le temps d'incubation.

Reçu en mars 1983.

Accepté en décembre 1983.

Remerciements. - Nous remercions Bernadette Chevalier, Michel Derouet et MarieThérèse Froux pour leur aide technique.

\section{Références}

AMER M. F., 1962. Embryonic mortality and malpositions in Fayoumi chickens. Poultry Sci., 41, $1707-1712$.

BEDNARCZYK M. F., COUDERT F., 1984. Influence de l'éclairement de l'embryon de poulet sur le taux d'éclosion, la durée d'incubation et l'hématopoïèse. Ann. Rech. vét. (sous presse).

BOHREN B. B., SIEGEL P. B., 1975. Light effects during incubation on lines of White leghorns selected for fast and slow hatching. Poultry Sci., 54, 1372-1374.

COLEMAN M. A., 1979. The effect of light during incubation and egg weight on hatch time and weight of broilers. Poultry Sci., 58, 1045 (Abstr.).

COLEMAN M. A., Mc DANIEL G. R., 1976. Changes in the energy sources and metabolites of photoaccelerated chick embryos. Poultry Sci., 55, 1591 (Abstr.).

LECLERCQ B., BLUM J. C., BOYER J. P., 1980. Selecting broilers for low or high abdominal fat : initial observations. Brit. Poultry Sci., 21, 107-113.

LEESON S., REINHART B. S., SUMMERS J. D., 1979. Response of White Leghorn and Rhode Island Red breeder hens to dietary deficiencies of synthetic vitamins. 2. Embryo mortality and abnormalities. Can. J. anim. Sci., 59, 569-575.

PEARSON R. A., HERRON K. M., 1982. Effects of maternal energy and protein intakes on the incidence of malformations and malpositions of the embryo and time of death during incubation. Brit. Poultry Sci., 23, 71-77.

SIMON J., LECLERCO B., 1982. Longitudinal study of adiposity in chicken selected for high or low abdominal fat content : further evidence of a glucose-insulin imbalance in the fat line. $J$. Nutr., 112, 1961-1973.

SIMON J., LECLERCQ B., 1983. Relation entre insulinémie et adiposité dans deux lignées de poulets rendus maigres ou gras par sélection. Rep. Nutr. Dévelop., 23, 443-451. 